\title{
Estatuto da Criança e do Adolescente (ECA), direitos formalmente reconhecidos e o sistema de garantias de direitos: três décadas de avanços e a (re)afirmação do "antigo"
}

\author{
Statute of the Child and of the Adolescent \\ (ECA), formally recognized rights and the \\ system of guarantees of rights: three decades of \\ advancements and the affirmation of the "old"
}

\author{
Carla Rosane Bressan* \\ Mayara Garcia** \\ Mikaela Lobo de Matos ${ }^{\star \star *}$
}

\begin{abstract}
Resumo: O Estatuto da Criança e do Adolescente (ECA/1990) representa o progresso nas discussões normativas, teóricas e sociais em relação à infância e adolescência no âmbito nacional e internacional. Após três décadas de sua promulgação denotam-se avanços, permanências e ainda possibilidades de (re)afirmação do "antigo", no atual contexto eivado de conservadorismo, impactando diretamente nas instituições e sujeitos que compõem o Sistema de Garantia de Direitos (SGD). Abordam-se elementos centrais do Sistema de Garantia de Direitos (SGD) e ações voltadas à garantia dos direitos, decorridas três décadas, registram-se avanços e permanências que necessitam de superação. Reflete-se ainda sobre questões que apresentam a possibilidade da (re)afirmação de princípios e práticas anteriores à aprovação do ECA. Os dados aqui apresentados derivam-se de fontes estatísticas de instituições públicas, trata-se de uma pesquisa de cunho documental. O presente texto consiste em uma síntese dos registros que compõem os projetos de pesquisa e de extensão em desenvolvimento desde o ano de 2015, vinculados ao Núcleo de Estudos da Criança, Adolescente e Família (NECAD).

Palavras-Chave: Estatuto da Criança e do Adolescente (ECA). Sistema de Garantia de Direitos. Avanços e continuidades.
\end{abstract}

\footnotetext{
* Doutora em Serviço Social - PUC/SP(2006). Professora Associada do Departamento de Serviço Social da Universidade Federal de Santa Catarina (UFSC), Coordenadora do Núcleo de Estudos da Criança, Adolescente e Família (NECAD). E-maill: bressan.carla@ufsc.br e crbressan@hotmail.com

${ }^{*}$ Graduanda do Curso de Serviço Social da Universidade Federal de Santa Catarina (UFSC), membro do Núcleo de Estudos da Criança, Adolescente e Família (NECAD). Participante do projeto de pesquisa. E-mail: mayaragarcia872@gmail.com

${ }^{* * *}$ Graduanda do Curso de Serviço Social da Universidade Federal de Santa Catarina (UFSC), membro do Núcleo de Estudos da Criança, Adolescente e Família (NECAD). Participante do projeto de pesquisa. E-mail: mikaela_lobo@hotmail.com
} 


\begin{abstract}
The Statute of the Child and of the Adolescent (ECA/1990) represents the progress in the prescriptive, theoretical and social discussions regarding the childhood and adolescence at national level and internationally. After three decades of his promulgation it shows advancements, permanences and still means of (criminal) affirmation of the "ancient one", in the current full conservatism context, impactando straightly in the institutions and subjects that compose the System of Guarantee of Rights (SGD). Board central elements of the System of Guarantee of Rights (SGD) and actions turned to the guarantee of the rights, passed three decades, it registers advancements and permanences that need overcoming. It thinks still about questions that present the possibility of the (criminal) affirmation of beginnings and practices previous to the approval of the ECA. The data here presented consist of a synthesis of the registers that composes the execution of the projects of inquiry and of extension in development from year of 2015 linked to the Nucleus of Studies of the Child, Adolescent and Family (NECAD).
\end{abstract}

Keywords: Statute of the Child and of the Adolescent (ECA). System of Guarantee of Rights. Advancements and continuidades.

Recebido em: 31/07/2020. Aceito em 31/10/2020.

\title{
Introdução
}

No presente ano estamos completando 30 anos de aprovação do Estatuto da Criança e do Adolescente - ECA (Lei nº 8.069/90), porém, pode-se afirmar que, no mínimo, há cinco décadas estamos vivenciando um movimento de construção dos fundamentos que norteiam o conceito de que crianças e adolescentes constituem-se em sujeitos de direitos. E, como tal, precisam ser considerados, abordados, tratados, seja nas instâncias de vivência da vida pública ou no âmbito privado (espaço familiar). Para quem é ou foi envolvido nesses movimentos, é muito desafiador refletir acerca da temática, uma vez que possuem um longo percurso histórico, que tem inúmeras nuances que lhes dão uma caracterização muito peculiar. História que não cabe nos limites do presente texto, contudo, não pode nem deve ser esquecida, especialmente considerando os desafios presentes e a lutas atuais, que evidenciam questões profundamente inquietantes para o campo da criança e do adolescente.

Por que se referenciou anteriormente cinco décadas? Porque o Estatuto sintetiza um momento e um movimento histórico significativo vivenciado no contexto brasileiro, fruto da convergência de diferentes movimentos, atuações de profissionais, de pesquisadores, de legisladores (dentre muitos outros) que vinham refletindo, experienciando, criticando e se desafiando a construir uma nova abordagem da infância e adolescência pautados em outros referenciais. Estes, em franca discussão no âmbito internacional, porém incipientes no contexto brasileiro dos anos setenta e primeira metade da década de oitenta.

Toma-se como referência exatamente este período em que a situação da infância e adolescência ganha forte visibilidade no contexto brasileiro, quando se instala uma busca na afirmação 
de direitos sociais e, mais especificamente, no reconhecimento de direitos humanos de crianças e adolescentes, pautados em um novo marco normativo-legal.

Concordando com inúmeros autores, a aprovação do ECA balizou mudanças em três níveis. Primeiramente em um novo marco legal, referenciado na Doutrina da Proteção Integral; segundo, no estabelecimento de um novo marco teórico, onde é recolocada a situação da criança e do adolescente na sua condição de "sujeitos em desenvolvimento", voltando-se então os olhares para o que é "ser criança e adolescente" em suas especificidades e peculiaridades; e, como terceiro (não menos importante), um marco social, em que a aprovação significou uma síntese de um processo histórico-social e cultural que demarca um momento de mudança. De lá para cá, pode-se afirmar que se tem registrado uma história de avanços/ afirmações e retrocessos/negações na concretização dos direitos de crianças e adolescentes então formalmente registrados.

Delimitado o marco referencial da discussão, o presente artigo se propõe a abordar criticamente elementos centrais do Sistema de Garantia de Direitos (SGD), como um conjunto de ações voltadas à garantia dos direitos e para o qual, decorridas três décadas, registram-se avanços, mas também ainda continuidades de princípios e práticas anteriores à aprovação do Estatuto da Criança e do Adolescente (ECA).

Para tanto, utilizar-se-á a metodologia de pesquisa documental. Segundo Gil (2006, p. 66) "[...] a pesquisa documental vale-se de materiais que não receberam ainda um tratamento analíti$\mathrm{co}$, ou que ainda podem ser reelaborados de acordo com os objetivos da pesquisa". Neste sentido, esse artigo orienta-se por meio de fontes descritivas, secundárias e retrospectivas, analisando arquivos particulares já compilados por instituições públicas.

Seguindo a lógica do que está proposto, pontuam-se as reflexões em dois momentos distintos. Abordam-se os fundamentos centrais do ECA e os princípios do SGD para, na sequência, tecer considerações acerca do que se pode considerar avanços (situando de modo especial as políticas de saúde, educação e assistência social), como também já sinalizando as continuidades, fundamentos e práticas ainda vinculados à lógica menorista. E, finalmente, aborda-se o que vai ser denominado de (re)afirmação do antigo, pois expressa um movimento crescente voltado a retomar práticas e conceituações já exaustivamente criticadas.

\section{O Estatuto Da Criança e do Adolescente - ECA e a perspectiva de um sistema articulador das ações voltadas à garantia dos direitos: 30 anos de avanços $e$ permanências/continuidades}

Embora indicada anteriormente, existe uma significativa história que sustenta o referido marco normativo que não cabe ser abordada nos limites do presente texto, mas que será referenciada em momentos considerados fundamentais para a compreensão como marco de ruptura ou alteração significativa. Toma-se, então, como ponto de partida desse momento, a aprovação do artigo 227 da Constituição Federal, que vai ser considerado a base inspiradora e definidora do desenho assumido pelo Estatuto. Segundo Antonio Carlos Gomes da Costa, esse artigo consolidou as perspectivas mais avançadas que estavam sendo discutidas no direito internacional, em que se indicava uma dimensão de condição da infância e adolescência, suas especificidades, como também se reafirmavam as distintas responsabilidades em relação a esse segmento. Manifesta "responsabilidades de todos" das mais diferentes instâncias da sociedade, voltadas à concretização 
dos direitos delimitados. Este artigo vai ser reproduzido textualmente, sob a forma do artigo $4^{\circ}$ do ECA. Assim:

É dever da família, da comunidade, da sociedade em geral e do Poder Público assegurar, com absoluta prioridade, a efetivação dos direitos referentes à vida, à saúde, à alimentação, à educação, ao esporte, ao lazer, à profissionalização, à cultura, à dignidade, ao respeito, à liberdade e à convivência familiar e comunitária. (BRASIL, 1990, art. $4^{\circ}$ )

Os direitos aqui afirmados ampliam a perspectiva do que significa este "sujeito" criança e adolescente, delimitando um padrão de necessidades a serem concretizadas que tem implicação direta no conceito de "sujeito em desenvolvimento" - princípio basilar da Doutrina da Proteção Integral. Esta tem como fundamento central que todas as crianças e adolescentes se encontram em um ciclo da vida que tem uma condição peculiar de desenvolvimento, implicando em necessidades e atenção específicas. E é responsabilidade do mundo adulto garantir as condições necessárias para este período.

Antonio Carlos Gomes da Costa (2011) chama a atenção, muito qualificadamente, sobre a lógica implícita na organização do Estatuto, e nunca é demais reafirmá-lo. Indica que o mesmo foi organizado mediante o princípio mais geral da proteção integral, que vincula-se à ideia da necessidade da garantia de um desenvolvimento integral deste "sujeito" que precisa de condições objetivas de desenvolvimento e aprendizagem. Dessa forma, sua organização está pautada em três eixos estruturadores: a) o eixo da Sobrevivência - que significa levar em consideração as necessidades mais fundamentais da condição de sobrevivência humana, ou seja, o direito à vida, à saúde e à alimentação; b) o eixo do Desenvolvimento Pessoal e Social - que significa as condições que precisam ser garantidas para que se atinja o processo de autonomia e identificação como um ser social, ou seja, direito à educação, à cultura, ao esporte e ao lazer e à profissionalização; e c) o eixo do Respeito e integridade física, psicológica e moral - que, como o próprio nome já indica, está vinculado à necessidade de recolocar a posição de crianças e adolescentes, que historicamente lhes foi reservada como o lugar de subjugação em relação ao mundo adulto, ou seja, o direito à liberdade, respeito, dignidade, convivência familiar e comunitária.

Dessa forma, no Título I (que corresponde praticamente a toda a parte geral do ECA) estão registrados os princípios gerais da doutrina, onde é explicitado que o Estatuto se coloca para todas as crianças e adolescentes, independentemente de sua condição social (opondo-se frontalmente ao que estava registrado até então nas versões dos Códigos de Menores), registrados aqui sob a forma de "direitos fundamentais". No referido título estão previstos os cinco capítulos de direitos fundamentais que, muito mais do que o registro de direitos na sua forma abstrata ou genérica, têm delimitadas necessidades, ações e responsabilidades concretas e objetivas. Temos: (I) Do Direito à vida, à saúde; (II) Do Direito à Liberdade, ao Respeito e à Dignidade; (III) Do Direito à Convivência Familiar e Comunitária; (IV) Do Direito à Educação, à Cultura, ao Esporte e ao Lazer; (V) Do Direito à Profissionalização e à Proteção no Trabalho. Nestes, é explicitado o papel da família e das políticas sociais básicas, onde o Estado tem um papel fundamental em sua proposição e execução.

Fruto dessa dimensão impressa pelo ECA, na primeira década após a sua aprovação, vai se impor a necessidade de reconhecer formalmente e estruturar o conceito de um Sistema de Garantia dos Direitos - SGD, dada a complexidade impressa à proposição feita. Neste sentido, para concretizar o que estava proposto no Estatuto, era necessária uma ação conjunta, coletiva, articulada, que vai muito além da mera ação de políticas setoriais que respondem exclusivamente 
e individualmente pelos seus setores. Mas estava implícita uma lógica de "ação" onde deveria haver corresponsabilidade, organização/ordenação conjunta e complementar. Esse indicativo permeou os debates das Conferências Nacionais da década de noventa e início dos anos dois mil, até que - fruto de deliberações das referidas conferências - em 2006, o Conselho Nacional de Direitos da Criança e do Adolescente - CONANDA aprova a Resolução n.113, em que "Dispõe sobre os parâmetros para a institucionalização e fortalecimento do Sistema de Garantia dos Direitos da Criança e do Adolescente".

O Sistema de Garantia de Direitos - SGD tem como essência o desenvolvimento de ações articuladas de instâncias públicas governamentais e da sociedade civil. É composto pelos eixos: I- Promoção - relacionado à elaboração e operacionalização de políticas sociais que são efetivadas por instituições de atendimento governamentais ou não governamentais; II - Proteção ou Defesa - refere-se a assegurar a concretização e eficiência da garantia dos direitos; e III- Controle Social - responsável pelo controle social realizado por organizações da sociedade civil que representam a população em entidades não institucionais, como fóruns, frentes, entre outros. Conforme Baptista (2012):

Para a implementação do sistema evidenciava-se a necessidade de repensar as ações e as inter-relações institucionais relacionadas às diversas situações em que crianças e adolescentes necessitam de proteção, de forma a garantir direitos, definindo mais claramente os papéis dos diversos atores sociais responsáveis pela operacionalização do Estatuto da Criança e do Adolescente e da Convenção das Nações Unidas sobre os Direitos da Criança, situando-os em eixos estratégicos e inter-relacionados. Evidenciava-se também a necessidade de fortalecer o controle externo e difuso da sociedade civil sobre todo esse sistema. (BAPTISTA, 2012, p.190).

Desse modo, tomando como referência o que está previsto no ECA e considerando a sua concretização, percebe-se que se impõe a necessidade do desenvolvimento das ações pautadas na lógica do SGD, demarcando a importância de ruptura com ações fragmentadas, desarticuladas, pressupondo estratégias de integração entre os diversos sujeitos, com seus conhecimentos teóricos e técnicos específicos. Com intuito de trabalharem de maneira orgânica e horizontal para responder às demandas das desigualdades sociais advindas do modo de produção capitalista (SCHULTZ; MIOTO, 2010). Em vista disso, observa-se a importância do reconhecimento dos diferentes atores sociais, como: Conselhos de Direitos, Conselhos Tutelares, entidades de atendimento e a área da justiça, de modo especial, os Juizados da Infância e Adolescência e Ministério Público. Portanto, é necessário que os atores do SGD possuam qualificação profissional e formação continuada, a fim de fortalecer o trabalho conjunto e eficaz, embasado na apreensão dialética da realidade, buscando compreender não apenas a aparência imediata, mas a essência da situação. Segundo Digiácomo (2011) é

[...] fundamental que os diversos integrantes do "Sistema de Garantias", independentemente do órgão que representam, tenham a qualificação profissional adequada e estejam imbuídos de um verdadeiro "espírito de equipe", tendo compromisso com a "proteção integral" das crianças e adolescentes atendidos, bem como a consciência de que, agindo de forma isolada, por mais que se esforcem não terão condições de suprir o papel reservado aos demais, não podendo assim prescindir da atuação destes. (DIGIÁCOMO, 2011, p.2). 
Aqui já se registra uma das primeiras fragilidades desse processo histórico. Identifica-se que é preciso avançar na atuação, de forma articulada, entre os diferentes atores desse sistema, quanto à necessidade da oferta de formação permanente, dentre outras anteriormente pontuadas.

Pensar nestas três últimas décadas (trinta anos de ECA) é um exercício desafiador, principalmente para não cair em fatalismos, reafirmando perspectivas reproduzidas na instância do senso comum, como, por exemplo, "a lei não serve de nada", que "tem a lei, mas ela não garante nada", ou ainda que "a lei é uma coisa e a prática é outra" e que "isso é assim e nunca vai mudar...", dentre outras corriqueiramente verbalizadas. Ao contrário do afirmado, parte-se da perspectiva de que temos três década de uma "desafiadora" construção histórica, que implicou em alterar dimensões concretas e objetivas, tais como a estrutura institucional, formas de organizar e desenvolver políticas, práticas institucionais e familiares, mudanças no aparato legal vigente, com novas orientações/regramentos (dentre outras), e implicou também em mudanças subjetivas/ culturais em relação à apreensão do espaço social desse ciclo de vida. Como movimento, pode-se perceber que não é um processo linear, nem meramente evolutivo, e muito menos simples de ser apreendido. Nesse sentido, ousamos afirmar que temos condições de apontar o que chamaremos de "avanços", quando estabelecemos uma relação com o que tínhamos anteriormente; como, também, o que chamaremos de "permanências" - para aquelas questões em que ainda não se avançou de forma significativa. E, quando muitas vezes sob a falsa aparência de novo/moderno, temos implícita a perspectiva anterior, pautada ainda na reafirmação dos princípios dos Códigos de Menores. Ou seja, ainda consiste em um grande desafio a sua superação.

No entanto, é pertinente já chamar atenção, também, dada a ascensão dos fundamentos do pensamento conservador vivenciado na última década (tanto no Brasil, como em contextos internacionais), que se descortina cada vez mais o risco de produzir "retrocessos". Ou seja, mesmo questões já consideradas como conquistas estabelecidas voltam a ser questionadas e a ser objeto de ataques e foco de constantes propostas de reformulações, servindo aos mais diferentes interesses. Podem-se registrar aqui, por exemplo, as declarações do então candidato à Presidência da República no pleito de 2018, quando um grande número de veículos de comunicação anunciou que "Bolsonaro diz que Estatuto da Criança e do Adolescente deve ser jogado na latrina - presidenciável fez o comentário após ser perguntado sobre denúncia de racismo no STF” (GAZETA ONLINE, 2018). Quando já no cargo, não faltaram situações de ataque e desqualificação do ECA (e tudo o que sua história representa), a exemplo da edição do Decreto 10.003/2019, publicado em 05/09/2019, no Diário Oficial da União (DOU), que tinha como finalidade extinguir o mandato, iniciado em março do referido ano, do Conselho Nacional dos Direitos da Criança e do Adolescente (CONANDA). Este altera o modo de funcionamento do referido Conselho, estabelece que os membros serão escolhidos por processo seletivo e não por eleição, e estabelecia ainda que o governo federal teria a maioria absoluta (com 13 membros) e a sociedade civil com nove representantes. Segundo reportagem da Rede Brasil atual, "[...] para o advogado e ex-conselheiro do Conanda Ariel de Castro Alves, na prática, essa medida liquida com o Conanda. Esse decreto significa uma extinção na prática do Conanda. Um ato ditatorial [...]" (REDE BRASIL ATUAL, 2019).

As intenções de alteração, modificação e adequação a outros interesses ainda têm como veículo, além do Executivo, o Legislativo, pois atualmente encontram-se tramitando 73 projetos de Lei na Câmara Federal que intencionam alterar o ECA, questão que será abordada no próximo item. Porém, é fundamental indicar aqui que, segundo a Associação Nacional dos Auditores Fiscais da Receita Federal do Brasil - ANFIP, "O Brasil encontra-se entre as dez maiores economias mais ricas do mundo e, ao mesmo tempo, possui uma das maiores concentrações de renda do planeta" (ANFIP, 2014, p. 16). Esses dados destacam a imensa desigualdade social e econômica do país, 
que incide diretamente nos indicadores sociais e políticas públicas da criança e do adolescente. Acrescido a este fato, em 2016 foi promulgada a Emenda Constitucional n 95, que limita o teto de gastos nas áreas da saúde, assistência social e educação, congelando e reduzindo o orçamento público para essas despesas primárias. Neste contexto, em 2018 foi eleito para o cargo de Presidente da República Jair Bolsonaro (somando 55,13\% dos votos), com a proposta de firmar um projeto político ultraliberal, articulado a um discurso fascista e conservador, com a constante recusa aos direitos, além da mercantilização das políticas sociais.

Na perspectiva de registrar os "avanços e as permanências/continuidades", tomam-se como referência os eixos estruturadores do SDG, mais especificamente o eixo da Promoção e o eixo da Defesa (responsabilização), por serem estruturadores e sistematizadores das políticas e ações dos diferentes atores do campo da criança e do adolescente. Dessa forma, será abordado o referido binômio no desenvolvimento de ações e intervenções que concretizam direitos, nos últimos trinta anos, chamando a atenção, principalmente, para as políticas de saúde, de educação, de assistência social - mais especificamente a programas e/ou projetos vinculados ao campo da infância e adolescência.

\section{Considerações acerca dos "avanços" e das "permanências" presentes no eixo da Promoção tendo em vista a garantia dos direitos}

É no eixo da Promoção que estão situadas as políticas sociais básicas que têm como finalidade proporcionar a atenção correspondente aos direitos assegurados no ECA; ou seja, operacionalizam-se a partir do desenvolvimento de "um conjunto articulado de ações governamentais e não governamentais" voltadas ao atendimento dos direitos da criança ou do adolescente, conforme previsto no artigo 86. Aqui, estão vinculados os responsáveis por formular, executar políticas voltadas à concretização dos direitos das crianças e adolescentes, como, por exemplo, Ministérios e Secretarias (ou órgãos correspondentes nas três esferas de governo) de Assistência Social, Educação, Saúde, Cultura, entre outros. Como, também, entidades de atendimento que prestam serviços nas mais diferentes instâncias, conforme previstas no artigo 90 e nas modalidades indicadas na forma da referida lei.

Segundo a publicação "Direitos Humanos de Crianças e Adolescentes - 20 anos do Estatuto", nos primeiros vinte anos um dos principais registros está no crescimento do investimento em políticas sociais básicas (como saúde, educação e assistência social), que refletiram diretamente na melhoria de indicadores sociais acerca da situação da criança e do adolescente no Brasil.

A referida publicação indica, por exemplo, que na área da Saúde ocorreu aumento de ações voltadas à qualidade de vida da criança e do adolescente. Pode-se referir também a quase total universalização do registro civil, com a emissão gratuita de certidão de nascimento. Igualmente, é merecedora de registro a queda da taxa de mortalidade infantil, que foi expressiva nas últimas duas décadas. No ano de 2000, a taxa de mortalidade era de 29,02 para cada mil nascidos vivos; em 2007 vai ser de 19,98 e em 2014 de 14,40 para cada mil nascidos vivos (IBGE, 2020), onde o aumento da cobertura pré-natal é indicado como um dos fatores preponderantes. Da mesma forma que ocorreram um aumento da cobertura vacinal e ações de combate à desnutrição infantil. Embora, no caso da cobertura vacinal (em que chegamos a atingir índices expressivos de cobertura no Brasil), nos dois últimos anos venha sendo indicada uma queda nesses índices, motivada pela falta de algumas vacinas no sistema público de saúde (situação que constantemente era abordada na mídia), como também a identificação de um movimento que se pode chamar de "contrários 
à vacinação de crianças" ou movimento antivacinas ${ }^{1}$ (disseminado nos mais diferentes países), levando pais ou responsáveis a negligenciarem essa responsabilidade. Essa situação tende a se agravar, pois, no atual contexto de pandemia de COVID-19, já se tem manifestações, por exemplo, do Conselho Nacional de Secretários de Saúde - CONASS de que essa "queda da taxa de imunização no Brasil" tem a tendência de aumentar, uma vez que pais e responsáveis têm diminuído a procura pela vacinação.

Dois outros índices que se constituem em indicadores sociais da condição da infância e adolescência brasileira são a desnutrição infantil e a gravidez na adolescência. No caso da primeira, segundo dados do Ministério da Saúde, embora a relação de déficit de altura/idade tenha sido reduzida pela metade entre 1996 e 2006 (de 13,5\% para 6,8\%) (BRASIL, 2020), mesmo com esse decréscimo, observa-se que isso não ocorreu de forma homogênea no Brasil, permanecendo este déficit concentrado em segmentos vulneráveis da população, como também em determinadas regiões. Uma confirmação disso está no indicativo de que em "crianças menores de cinco anos pertencentes a famílias beneficiárias do Programa Bolsa Família, verifica-se que tanto a desnutrição aguda (baixo peso) quanto a crônica (baixa estatura) são mais prevalentes quando comparadas aos dados de toda a população brasileira nessa faixa etária" (BRASIL, 2020).

No que se refere à gravidez na adolescência, essa é uma questão em que pouco se avançou no Brasil. Segundo o Relatório "Maternidade precoce: enfrentando o desafio da gravidez na adolescência" (2013), a taxa de natalidade das adolescentes brasileiras entre 15 e 19 anos foi de 71 em cada mil, dado que se aproxima à situação de país onde a prática cultural é de as meninas casarem muito jovens, diferentemente de outros países onde a média é de 12 a 15 a cada mil. Ressalta-se que esse é um debate que precisa ser enfrentado no Brasil, pois os dados indicam que a gravidez na adolescência está vinculada à baixa renda, situada na maioria das vezes em jovens periféricas, que têm baixas expectativas de acessos educacionais, de profissionalização e, por que não dizer, de "afirmação social", onde a principal alternativa disponível está em dar início à formação de um núcleo familiar, por isso, um grande número delas se coloca como uma "gravidez consentida". É importante registrar que mães adolescentes correm riscos de estarem sendo colocadas em condições de menos acessos a direitos fundamentais básicos, como educação básica, possibilidade de formação profissional, ao trabalho e também ao lazer - uma vez que, na maioria, as propostas desenvolvidas pelas respectivas políticas não levam em consideração a condição da adolescente mãe.

No âmbito da Educação, embora se tenha um conjunto de indicadores importantes para demarcar a organização da política, registram-se aqui, principalmente, dados que são considerados importantes para demonstrar um crescimento da atenção, que estão registrados no aumento da taxa de matrícula e dos índices de permanência na escola, onde significará dizer que ocorreu aumento da escolarização de crianças e adolescentes; o que responde à máxima cotidianamente repetida, desde a aprovação do ECA, de que "o lugar da infância e adolescência é na escola"2.

Nesse sentido, segundo dados do Censo Escolar/INEP 2016 registrados no "Anuário Brasileiro da Educação Básica” de 2018 (BRASIL, 2018), o total de matrículas na educação básica em redes

\footnotetext{
${ }^{1}$ Para mais informações consultar: https://www.conass.org.br/consensus/queda-da-imunizacao-brasil/

${ }^{2}$ Nesse sentido, há uma dicotomia em relação à educação. Ou seja, concomitantemente ocorre um movimento intenso de luta para a garantia do direito à educação, pautando na escola pública de gestão pública, laica e de qualidade; e, em contraponto, acontecem sucessivas reformas neoliberais que instigam a privatização e a mercantilização no âmbito da educação, a exemplo da Emenda Constitucional nº 95 de 2016, que limita o teto de gastos nas áreas da saúde, assistência social e educação, congelando e reduzindo o orçamento público para essas despesas primárias.
} 
públicas e privadas no ano de 2016 foi de 48.817.479, concentrando o maior número de matrículas no ensino fundamental (27.691.478).

O referido documento aponta, a partir de dados do IBGE/PNAD contínua (2017), que a taxa de alfabetização da população com 15 anos ou mais, que era de 91,4\% em 2012, passou para 93,1\% em 2017. 0 que demonstra o caminho que vem sendo feito desde o período da aprovação do ECA, quando tínhamos uma taxa de analfabetismo de adolescentes (entre 15 e 17 anos) de 8,16\% em 1992, que decresceu para 1,7\% em 2008 (PNAD, 2008 apud SDH, 2010, p.92). Como consequência dessas décadas de diminuição do analfabetismo funcional ${ }^{3}$ e aumento da alfabetização, temos um aumento da taxa de escolarização de 7 a 14 anos de idade (crianças e adolescentes), que em 1992 estava em 86,6\% e passou para 97,9 em 2008 (PNAD, 2008 apud SDH, 2010, p.91). Situação que vai refletir diretamente nas idades seguintes na década subsequente, quando, segundo os dados do IBGE/PNAD contínua (2017), ocorreu um aumento na escolaridade média entre a população de 18 a 29 anos, que em 2012 era de 9,7 anos e em 2017 ampliou para 11,3 anos.

Com alicerce na análise dos dados pontuados anteriormente, é necessário sinalizar que é praticamente consenso na literatura da área que majoritariamente a elevação nestes índices decorreu da implantação e implementação de programas governamentais, a exemplo, o Bolsa Família. Estes articulam a sua oferta à condição da presença na unidade escolar. Requisito discutível e por vezes contestável, contudo, é inegável o aumento significativo da presença de crianças e adolescentes de classes pauperizadas na escola pública. Porém, também é importante aqui registrar que, muitas vezes, em muitos contextos, é "infelizmente meramente formal"; ou seja, o movimento da entrada e da permanência na escola (via matrícula) não foi acompanhado de um movimento qualitativo de melhoria da qualidade da educação. Aqui podem-se apontar desde situações estruturais como infraestrutura da escola, valorização de professor da educação básica, com plano de carreira adequado, até a atualização em metodologias pedagógicas, dentre outros. Condicionantes que demandam maior investimento na Política Educacional, em período de intensificação da ofensiva ultraliberal, em que a educação tende a se reestruturar diante do modelo proposto, direcionando-se a uma lógica de privatização e mercantilização, sucateando e precarizando as instituições escolares de caráter público e vigorando as da rede privada - assim, a educação perde seu princípio de direito e adquire o caráter de mercado, voltando-se qualitativamente apenas a crianças e adolescentes oriundos da classe burguesa. Isto posto, vê-se outra esfera de luta na direção da concretização do direito à educação.

$\mathrm{Na}$ esfera referente ao reconhecimento do direito de crianças e adolescentes com deficiências e/ou transtorno mental, desde a promulgação da Constituição Federal de 1988 houve um crescimento expressivo no campo normativo, com a aprovação de regulamentações específicas (como leis, portarias, decretos, etc.) que fortalecem a garantia dos direitos individuais e sociais das pessoas com deficiência. Dentre estas, pode-se dizer que a criação da Política Nacional da Pessoa Portadora de Deficiência (Portaria nº 1.060/GM/2002) e a Lei Brasileira de Inclusão da Pessoa com Deficiência, também conhecida como Estatuto da Pessoa com Deficiência (Lei no 13.146/2015), são consideradas marcos balizadores desse debate. Entretanto, salienta-se que é necessário avançar em diversos pontos para a efetivação dos direitos contidos nestas legislações, rompendo com barreiras arquitetônicas e urbanísticas, alterando espaços físicos para que prevejam acessibilidade, tal como questões sociais e comunicativas relacionadas ao preconceito, discriminação.

\footnotetext{
${ }^{3}$ Conforme Ribeiro (1997), o termo “analfabetismo funcional” é empregado para indicar a capacidade de utilizar a leitura e escrita apenas no limite de dar resposta para as finalidades práticas das situações cotidianas.
} 
Quanto a questões específicas de crianças e adolescentes com deficiência, além dos avanços normativos e legislativos, identifica-se o crescimento do "movimento de inclusão" nos variados espaços de convívio social, principalmente na educação formal. Deste modo, o documento “Anuário Brasileiro da Educação Básica” (BRASIL, 2018) assinala que em 2016 ocorreu um total de 971.372 matrículas de crianças e adolescentes com deficiência, sendo 796.486 desses matriculados em classes comuns e 174.886, em classes especiais ou escolas especializadas. Indica ainda que, referente a esta questão, o Programa Benefício de Prestação Continuada (BPC) na Escola possui a incumbência de acompanhar a permanência na escola de crianças e adolescentes cuja família receba o auxílio. Conforme a Nota Técnica Conjunta nº 2/2018 (BRASIL, 2018), no ano de 2017, no Brasil, 65,32\% dos beneficiários encontravam-se na escola e 34,68\% estavam fora do ambiente escolar. O que evidencia a necessidade de um avanço significativo na área de atenção do direito à educação para esse segmento.

Porém, se no campo das atenções que podem ser chamadas como "clássicas", como vacinas, desnutrição, vagas em escolas, acessibilidade, dentre outras, os índices foram se alterando de forma significativa, por outro lado, há significativos desafios para a concretização de outros direitos fundamentais, como, por exemplo, no campo do "direito à vida", onde acidentes e a diversas formas de violência contra este segmento seguem em elevados índices. Segundo o relatório "Viva: Vigilância de Violências e Acidentes", no ano de 2013 foi registrado um total de 29.784 notificações de violências contra crianças entre zero e 9 anos de idade, sendo 13.867 meninos e 15.917 meninas. Nos registros é indicado que $50 \%$ das violências foram caracterizadas como "negligência" . Em relação à raça/cor, evidencia-se que 39,2\% foram identificados como brancos; $35,1 \%$, pardos; 5,91\%, pretos; 0,4\%, amarelos; e 0,8\%, indígenas. Destes, $91,7 \%$ residiam nas áreas urbanas. (BRASIL, 2017)

Em relação aos adolescentes de 10 a 19 anos, foi registrado um total de 50.634 notificações de violências, sendo 17.886 do sexo masculino e 32.748 do sexo feminino. No que tange à raça/ cor, $36,7 \%$ identificaram-se como pardos; $36,5 \%$, brancos; $8,0 \%$, pretos; $0,7 \%$, amarelos; e 1,0\%, indígenas. Quanto à escolaridade destes, 10,5\% dos adolescentes atendidos cursaram de zero a 4 anos de estudo; 29,5\%, entre 5 e 8 anos; e 18,7\%, entre 9 e 11 anos. Cabe salientar que, dentro das 14.943 notificações de indivíduos com 5 a 8 anos de escolaridade, 10.527 (70,4\%) são de adolescentes de 10 a 15 anos, que estão, portanto, com a faixa de escolaridade esperada. Destes, 76,7\% dos atos de violência ocorreram na área urbana. (BRASIL, 2017, p. 171)

Dentro da caracterização da violência, encontra-se um conjunto de formas ou modalidades, porém, os homicídios têm ocupado lugar central na maioria das estatísticas brasileiras. Tomando como referência o 5ํㅡㄹ Relatório Nacional sobre os Direitos Humanos no Brasil (2001 2010) - publicado pelo NEV-USP, cerca de 53.000 crianças e adolescentes morreram vítimas de homicídios em 2002. Nessa mesma década (em 2006), segundo os dados registrados no "Sistema de Vigilância de Violências e Acidentes - VIVA", implantado pelo Ministério da Saúde em 2006 (que possibilita monitorar os atendimentos por "violência" nos serviços de saúde), a principal causa de morte de adolescentes entre 12 e 18 anos no Brasil foi o homicídio, responsável por 45\% dos óbitos (SDH, 2010, p.82)

Segundo o relatório "Violência Letal Contra Crianças e Adolescentes no Brasil" produzido por Waiselfisz (2015), em relação ao perfil das vítimas de homicídios registrados no ano de 2013, tem-se que 88,9\% eram do sexo masculino e 11,1\%, do sexo feminino. Em relação à cor/raça nas

${ }^{4}$ Chama-se a atenção para a escassez de produção teórica que vislumbre discutir e delimitar o conceito de "negligência", dada a amplitude deste conteúdo. 
mesmas faixas de idade, tem-se que 4,7\% destes eram brancos, enquanto 13,1\% eram negros (ambos os índices variam de acordo com estados e municípios). Aliado a estas características, registra-se que no Brasil 78,2\% dos homicídios de crianças e adolescentes revelaram ter participação de armas de fogo, enquanto $10 \%$ foram por objetos cortantes/penetrantes; $5,6 \%$, outros meios; $3,5 \%$, objeto contundente; 1,9\%, estrangulamento/sufocação; e 0,8\%, força corporal. (WAISELFISZ, 2015:99)

Em seus estudos, Waiselfisz (2015) ainda revela que o Brasil ocupa a 3ํㅗ posição no ranking de países - entre 85 países - com maior índice de homicídios contra crianças e adolescente. Debruçando-se sobre estes dados, observa-se que as taxas de homicídio aumentaram em 426,9\% nas últimas quatro décadas (entre 1980 e 2013), ou seja, o equivalente a um total de 207.438 mortes entre as faixas de 1 a 19 anos de idade (faixa utilizada pelo autor), nos respectivos períodos. Em 2013 foram registrados 10.520 assassinatos contra crianças e adolescentes no país, "quase 29 vítimas por dia”. Considerando todas as causas de óbitos (acidentes por transportes, outros acidentes, suicídios, homicídios, causas externas e causas naturais), no ano de referência foram contabilizados 75.893 homicídios no Brasil. Há de se registrar que, durante o primeiro ano de vida, 97,7\% das mortes são derivadas de causas naturais, fato que decai quantitativamente entre a população com a faixa de 14 a 18 anos, registrando o pico nesta última faixa, equivalente a 77,5\% de mortes por causas externas. Nas últimas faixas já consideradas, o homicídio representa 2,5\% do total de mortes até os 11 anos; 6,7\% aos 12 anos; $14,0 \%$ aos 13 anos; 25,1\% aos 14 anos\%; até alcançar o pico aos 17 anos, com 48,2\%, decaindo posteriormente. No mais, na década de 2003 a 2013, o número de homicídios cresceu 19,7\% e entre 2012 e 2013, 3,6\%. (WAISELFISZ, 2015: 59-62)

Estes dados indicam a urgente necessidade de instituir políticas públicas preventivas no sentido de apreender as diferentes situações que na última década têm apresentado expressivo aumento. Seguramente, o enfrentamento da questão do homicídio de crianças e adolescentes, na maioria meninos, negros e moradores da periferia, consiste no que poderíamos chamar da ponta do iceberg, uma vez que, necessariamente, terão que ser abordadas questões como as condições de sobrevivência, renda, acesso à escola, saúde e moradia (por exemplo) da grande maioria da população brasileira, o que é papel dos diferentes atores do SGD (de modo especial, nesse eixo da promoção), em propor e executar políticas de atenção nas referidas áreas. Além disso, é importante registrar a ausência de propostas voltadas ao esporte, cultura, lazer e escola em período integral, vislumbrando o enfrentamento destas questões, vistas como uma das expressões da questão social contemporânea.

\section{Considerações acerca dos "avanços" e dos desafios presentes no eixo da Defesa tendo em vista a garantia dos direitos}

O eixo da Defesa, ou também denominado da Proteção, está associado ao acesso à justiça. Este tem como finalidade promover o acesso às instâncias públicas de vigilância e aos mecanismos jurídicos de proteção dos direitos humanos de crianças e adolescentes. Este eixo vai estar vinculado às diferentes instâncias do poder Judiciário (Varas da Infância e da Juventude; Promotorias de Justiça, dos Centros de Apoio Operacional, das Procuradorias de Justiça, Ministério Público, Ouvidorias), Polícia Civil, Polícia Militar, Conselhos Tutelares, como também os setores da sociedade civil voltados à defesa dos direitos humanos.

De acordo com a publicação da Secretaria de Direitos Humanos (2010), já na primeira década de aprovação do ECA cresceu a atuação dos referidos setores, desenvolvendo ações voltadas à garantia do direito legal de crianças e adolescentes. Dentre os diferentes atores sociais acima 
nominados, identifica-se o expressivo envolvimento do Ministério Público, principalmente nas questões relacionadas à oferta de serviços públicos voltados a esta população.

O ECA inovou ao propor uma instância de âmbito municipal que tem como função primordial zelar pelos direitos da criança e do adolescente, tendo a função de um defensor de seus direitos, seja frente ao Estado, à família ou à sociedade. Esta consiste no Conselho Tutelar - CT, que pode ser apontado como uma das principais referências no campo da defesa dos direitos, quando considerado que, na instância dos pequenos municípios, são (ou deveriam ser) a principal referência para famílias, escolas, poder público, equipamentos sociais quanto ao desenvolvimento de ações voltadas à garantia da concretização do previsto no ECA.

Na primeira década de aprovação do ECA ocorreu uma crescente instalação dos Conselhos Tutelares (conforme nele previsto). Porém, segundo dados do Cadastro Nacional de Conselhos Tutelares, ainda não se conta com Conselhos Tutelares suficientes e/ou na quantidade conforme prevista em lei. O Cadastro indica que:

[...] no Brasil [há] 5.906 Conselhos Tutelares estruturados, [ou seja] 632 a menos do que seria necessário para garantir a proporção de um conselho para cada 100.000 habitantes de cada município recomendada pela Resolução 139 do Conselho Nacional dos Direitos da Criança e do Adolescente - Conanda. Neste contexto, 277 municípios têm menos conselhos do que o recomendado, o que representa $5 \%$ do total. Tal déficit foi calculado subtraindo o número de conselhos existentes do número de conselhos necessários. (BRASIL, 2013, p. 11).

Para além da quantidade numérica de CTs, dois grandes desafios estão colocados ainda: o primeiro deles está na constituição da infraestrutura dos referidos conselhos. As condições materiais objetivas têm sido objeto de vários debates nesse campo, pois são levantados desde falta ou equipamentos obsoletos, até salas inadequadas ao desenvolvimento das atividades. O segundo está na adequada e permanente formação para o exercício da função, uma vez que seus membros são eleitos de forma direta, no âmbito municipal, e nem sempre possuem qualificação específica para atuação na área. Há que se garantir a oferta de formação permanente e qualificada aos CTs, o que vai refletir diretamente na qualidade do serviço prestado. Mesmo assim, pode-se afirmar que o Conselho Tutelar se tornou uma referência para a população, como espaço de busca para aplicação do direito, funcionando, por vezes, como uma espécie de "ouvidoria" do município.

Outra problemática está em qualificar progressivamente este mecanismo de denúncia já instituído. Visto que, segundo a SDH (2010:128), as demandas mais habituais nos Conselhos Tutelares relacionam-se à violação de direitos. Destas, 34,12\% são relativas ao direito à educação; $22,18 \%$, ao direito à saúde; $14,67 \%$, ao direito à vida; e 10,58, ao direito à dignidade, dentre outros.

O crescente aumento das denúncias revela outro divisor de águas no debate dos direitos de crianças e adolescentes. Este fenômeno expressa um maior reconhecimento social para o tratamento digno de sujeitos de direitos. Deste modo, foi elaborado, em 1997, pela Associação Brasileira Multidisciplinar de Proteção à Criança e ao Adolescente (ABRAPIA), um portal de denúncia, intitulado Disque 100. Em 2003 o Governo Federal tornou-se responsável pelo serviço, o que gerou um aumento significativo do número de denúncias em relação à violação de direitos de crianças e adolescentes. De acordo com Paraná (2020), a partir da transferência de responsabilidade, o Disque 100, além de ser um portal de denúncias, introduziu uma rede com serviços e parceiros para a prevenção e garantia dos direitos da infância e adolescência. 
Somente no período entre 2003 e outubro de 2010, foram registrados mais de 2,53 milhões de atendimentos e encaminhadas 140,1 denúncias, provenientes de 4.885 municípios, representando $88 \%$ das cidades de 27 unidades federativas do país. As denúncias mais frequentes foram negligência (34\%), seguida por violência física ou psicológica (34\%), e violência sexual (32\%). (SDH, 2010, p.122).

Em virtude do desenvolvimento desse canal de denúncias e com a ampliação das notificações, é dada visibilidade às novas questões do campo da infância e adolescência, tais como: negligência, violência sexual, estupro, violência doméstica, trabalho infantil, entre outros, com novos desafios em relação a concepções, abordagens e intervenções. Nesta perspectiva, com o surgimento dessas demandas para os profissionais da rede de atendimento, estes assuntos têm sido recorrentes temáticas de pesquisas, eventos, estudos para compreender a articulação e integração das atuações entre os atores do SGD. Todavia, ainda se tem uma problemática no sentido de transformar as denúncias que chegam via disque 100 em ações efetivas no interior das políticas sociais básicas, construindo ações preventivas e protetivas contra essas violações de direitos constituídos histórica e socialmente.

Neste conjunto de novas perspectivas e ações, uma questão que é extremamente desafiadora e registra pouquíssimos avanços é a situação de adolescentes em conflito com a lei. A construção do Sistema Nacional de Atendimento Socioeducativo - SINASE, de 2006 (Lei no 12.594/12), possui uma direção garantista, considerando o devido respeito ao processo legal, para estabelecer a responsabilidade individual de adolescentes em decorrência da prática de ato infracional - conforme sinalizado pelo ECA. O SINASE precisa ser compreendido como um instrumento balizador da gestão pedagógica do atendimento socioeducativo, buscando estabelecer a divisão de responsabilidades entre as variadas instâncias governamentais.

Em vista disso, sinalizam-se dois pontos principais em relação às situações de adolescentes em conflito com a lei. O primeiro refere-se à transferência para os municípios da incumbência das medidas socioeducativas em meio aberto, ficando associadas à política de assistência social, mais especificamente, no âmbito da proteção social de média complexidade. Esta alteração para o âmbito municipal ocasionou fragilidades e dificuldades quanto à própria infraestrutura da política para atender essas demandas, além da questão da capacitação e formação dos profissionais que prestam serviços nesse locus. Nesse sentido, aponta-se a necessidade de estudos, pesquisas com base reflexiva e crítica que pontuem a atuação profissional nessa área, elaborando novos referenciais para a intervenção qualificada a esse segmento. O segundo diz respeito à "falência" do sistema socioeducativo de meio fechado em grande parte dos estados, onde, apesar dos avanços legais de superação da FEBEM, constata-se a sobrevivência de velhas práticas: insalubridade, superlotação, falta de qualificação dos profissionais, falta de profissionais e propostas educacionais questionáveis que dificilmente pautam-se no princípio educativo, conforme previsto no ECA.

Essas fragilidades têm chamado cada vez mais a atenção no que se refere à priorização do cumprimento de medidas socioeducativas em meio fechado, contrariando os princípios mais elementares do Estatuto. Diferentes estudos indicam que o "encarceramento" de adolescentes tem prevalecido como uma das principais ferramentas de ressocialização. O Plano Nacional de Atendimento Socioeducativo - Diretrizes e Eixos Operativos para o SINASE (2013) aponta o aumento da taxa de restrição e privação de liberdade entre os anos de 2010 e 2011; se no primeiro os dados representam 4,5\%, no ano seguinte representam 10,6\% (BRASIL, 2013). Estudos como o de Tejadas (2005) apontam que boa parte do aumento de internações está relacionada à "produção de reincidências" realizadas pelo próprio sistema, pois ele deixa a desejar nas propostas 
pedagógicas desenvolvidas, seja no desenvolvimento das medidas em meio fechado, como também no cumprimento em meio aberto.

Determinadas práticas (fundamentadas ainda na perspectiva do Código de Menores) têm sobrevivido ao longo das referidas décadas e recebem as mais diferentes justificativas, que vão desde a falta de condições estruturais na organização das propostas, falta de formação dos profissionais que atuam na área, até perspectivas conceituais e/ou ideológicas em que se partilha outra perspectiva de sociedade, da relação entre adulto-criança e papel do Estado. Observa-se que, em algumas questões, trata-se de situações que estão em uma dimensão mais objetiva e operacional, como, por exemplo, a necessidade de formação e capacitação continuada para os diferentes atores do SGD; ou, ainda, investimento público mais significativo que subsidie ações concretas e de qualidade abrangendo aspectos voltados à garantia dos direitos fundamentais de crianças e adolescentes contidos no ECA.

No entanto, para além dessa dimensão mais prática e objetiva, impõe-se ainda a necessidade de estudos, pesquisas que abordem as questões que serão indicadas no item que se segue, que denominamos de permanências desafiadoras ou ainda a possibilidade de (re)afirmação do antigo. Isso se deve ao cenário nacional vivenciado na última década, onde é identificado o avanço significativo do pensamento conservador, vinculado diretamente a um referencial ideológico e cultural profundamente criticado nas décadas de oitenta e noventa, na perspectiva de superação da concepção menorista vigente.

\section{Permanências desafiadoras e a possibilidade da (re)afirmação do "antigo"}

Tomando como referência as questões abordadas anteriormente, onde foi sinalizado mais especificamente o que precisa ser abordado ou enfrentado no âmbito das referidas políticas sociais, cabe chamar a atenção para questões que são mais amplas, gerais, e que cortam transversalmente a dimensão de direitos reafirmados no ECA.

Estas estão mais diretamente vinculadas ao que se pode denominar de possibilidade de retrocesso, ou de "reafirmação do antigo". As mesmas, dada a sua amplitude (por não afetarem um ou outro direito ou campo de uma política exclusivamente), têm uma característica de "contramovimento" ou ainda de movimento contrário à lógica construída nas três últimas décadas.

Considerando essa dimensão de transversalidade ou também de seu sentido generalista (de não afetar um direito em específico ou uma dada política), podemos registrar quatro principais questões que emergem com muita força no final desta terceira década de aprovação do ECA. São elas: a defesa da redução da maioridade penal; a reafirmação da "lógica do trabalho" como alternativa de "educação" dos adolescentes; a "culpabilização das famílias" pela condição e forma de atuação junto aos seus filhos; e, finalmente, as propostas de alterações ao ECA em tramitação na Câmara Federal (em 2019) sob a forma de Projetos de Lei (PLs), que representam a expressão concreta do "contramovimento", dadas as características das propostas advindas dos partidos políticos que as apresentam.

No que se refere à primeira questão indicada, temos acompanhado, principalmente na última década, um crescente movimento em defesa da redução da maioridade penal, inclusive com campanha midiática que tem exclusivamente a finalidade de fabricar consenso acerca da matéria. De uma forma mais desavisada, pode parecer que é apenas uma situação simples e numérica relativa à idade, onde se argumenta que, "como os jovens podem votar aos 16 anos, também podem responder pelos seus atos com essa idade" - isso quanto às propostas que defendem sua 
redução para essa idade, embora haja outras indicando um rebaixamento maior. Pensamento que tem se fortalecido, se observarmos a ascensão e fortalecimento do pensamento conservador na tessitura social.

A temática da redução da maioridade penal é controvertida e de difícil resolução. De um lado, tem ampla defesa de que o artigo constitucional 228 prevê a inimputabilidade dos menores de 18 (dezoito) anos e, como tal, estão sujeitos à legislação específica, mais especificamente, desde a aprovação do ECA (1990), sob a forma de medidas socioeducativas. Este é considerado um direito individual e, assim, tem a proteção da imutabilidade que rege o artigo 60, § 4ำ IV da Constituição Federal, as chamadas cláusulas pétreas, podendo ser alteradas apenas em um processo de revisão constitucional. De outro lado, temos aqueles que contra-argumentam essa perspectiva (não as compreendendo dessa forma), porém reconhecem que esse é um embate difícil e desgastante de ser travado. Dessa forma, é considerado caminho mais fácil e mais prático alterar diretamente as medidas previstas no ECA.

Essa perspectiva pode ser observada, por exemplo, no levantamento feito acerca dos PLs que tramitam na Câmara Federal, pois, dentre os 73 Pls em tramitação no mês de outubro de 2019, 10 tinham como foco da alteração artigos do ECA que tratam da prática do Ato Infracional (do artigo 103 ao 130). Esta perspectiva propõe alterações no tempo de cumprimento das medidas socioeducativas, aumento no tempo de internação, mudanças na caracterização da internação, dando ênfase à formação para o trabalho de meninos e meninas que respondem por medidas socioeducativas.

Resguardadas as devidas diferenças (de marco temporal e legal), os dois Códigos tinham como princípio central que o sujeito é o "problema" e como tal precisa ser "tratado". Que os "menores" são uma ameaça social e a representação de perigo social; ou, ainda, a perspectiva do Código de 1979 de "sujeito em situação irregular", onde estes eram tomados como um "problema social”. Conceitos clássicos pautados nos princípios dos Códigos de Menores (1927 e 1979). Ou seja, nas palavras de Silva (2005), as críticas aos códigos de menores podem ser agrupadas em duas:

A primeira delas é que crianças e adolescentes chamados, de forma preconceituosa, de "menores" eram punidos por estar em "situação irregular", pela qual não tinham responsabilidade, pois era ocasionada pela pobreza de suas famílias e pala ausência de suporte e políticas públicas. A segunda era referente às crianças e adolescentes apreendidos por suspeita de ato infracional, os quais eram submetidos à privação de liberdade sem que a materialidade dessa prática fosse comprovada e eles tivessem direitos para sua devida defesa, isto é, inexistia o devido processo legal. Nesse sentido, era "regulamentada" a criminalização da pobreza. (p.33)

Não se tem dúvidas de que está em curso uma tentativa de (re)afirmação do conceito pautado na perspectiva do "controle social", ou ainda de uma versão atualizada de "higiene social", vivenciada nas duas primeiras décadas do século passado no Brasil. Reafirma-se aqui a atuação do Estado que assume o papel de "Estado penal" nos moldes indicados por Wacquat (1994), com uma crescente diminuição no investimento de recursos públicos em políticas sociais, porém um significativo aumento do aparato repressor onde a população pobre, com baixa escolaridade, majoritariamente negra e moradora das periferias é o "alvo" direto. Onde estes adolescentes precisam ser "controlados", separados e direcionados ao mundo do trabalho.

Conforme indicado anteriormente, temos aqui um embate em uma dimensão muito mais ampla do que meramente a alteração de regra de faixa etária, pois o que está posto é a volta à 
lógica clássica de que "o problema está no próprio sujeito", não trazendo para a frente do debate quem são esses sujeitos, sob que condições vivem, que acessos são proporcionados pelas políticas sociais básicas, enfim, entender de forma concreta como se dá a construção social da realidade de um país que vive sob a égide de um capitalismo dependente. Não tomar essas questões sob essas dimensões consiste em um grande retrocesso, que impactará diretamente na elaboração das propostas de atenção a crianças e adolescentes (via políticas sociais básicas), como também na atuação dos profissionais nos mais diferentes campos de intervenção.

A segunda questão que se coloca como reflexão está na reafirmação da "lógica do trabalho" como alternativa de "educação" dos adolescentes. É cada vez mais preocupante a crescente retórica de que o "trabalho" traz em si uma espécie de "salvo conduto" para a passagem do mundo da infância e da adolescência para a "conquista" da vida adulta. Nesse sentido, a questão da exploração do trabalho infanto-juvenil pode ser considerada uma das questões mais difíceis de enfrentar no contexto brasileiro. Principalmente, porque existe um referencial cultural e socialmente construído sob as ideias de que, "enquanto estiver trabalhando", não está se envolvendo em outras coisas, de que "trabalho" é "coisa boa" e que "dignifica o sujeito". Da mesma forma que a questão anterior, sem apreender a questão em sua complexidade. Ou seja, por que um número significativo de crianças e adolescentes é levado a trabalhar? A substituir a possibilidade do direito à educação, à cultura, ao esporte e ao lazer - por exemplo, para serem inseridos no mundo da exploração como mão de obra?

Embora os dados brasileiros tenham registrado a redução da exploração do trabalho infanto-juvenil nas referidas três últimas décadas, os mesmos ainda se mantêm em índices elevados. Segundo a Pesquisa Nacional por Amostra de Domicílios (PNAD/2016), que realizou o diagnóstico voltado à temática do trabalho infantil, os dados apontam que, de um total de 40,1 milhões de crianças e adolescentes entre as faixas etárias de 5 a 17 anos, 1,8 milhão $(4,6 \%)$ estava em situação de trabalho infantil no país. Este montante concentra-se em maior número na faixa etária de 16 e 17 anos, somando um total de $17 \%$, seguido por 6,4\%, entre 14 e 15 anos. No que concerne aos dados do trabalho infantil relativos à distinção de sexo e raça, no Brasil, 65,3\% são do sexo masculino e $34,7 \%$, do sexo feminino. Quanto à raça, $35,9 \%$ são brancos e $64,1 \%$ são pretos e pardos (PNAD, 2016).

Aliada a essas condições de trabalhadores, temos outra questão que muito raramente é discutida e/ou tem pouquíssima visibilidade, que são os acidentes de trabalho. Para se ter uma dimensão da situação, entre os anos de 2007 e 2017 foram registrados 40 mil acidentes de trabalho entre crianças e adolescentes, dos quais 24.654 foram graves, com faturas e amputações de membros. Nesse mesmo período, foi registrado também um total de 236 mortes de crianças e adolescentes em seu exercício de laboral. (DIÁRIO CATARINENSE de 12 de junho 2018)

Em contrapartida, são fracos e frágeis os enfrentamentos referentes às questões do trabalho infanto-juvenil pautados na vigilância e/ou denúncia das situações, o que caracteriza muito mais uma prática pontual e diretamente localizada. Infelizmente, essa instância de atuação ainda tem sofrido ataques e tentativas de flexibilização da legislação vigente. Por outro lado, cabe aqui também perguntar por que uma das alternativas encontradas para atuar com crianças e adolescentes está sendo a preparação para inserção no mercado de trabalho, a exemplo da política de assistência social.

Novamente, vamos afirmar - essa perspectiva não é nova! Novamente vemos se fortalecendo conceitos clássicos e também criticados, temos aqui outro exemplo clássico de reafirmação do antigo, embora, muitas vezes, com aparência de algo novo e característica de moderno, que, 
conforme indicado anteriormente, com o fortalecimento do pensamento conservador, encontra largo caminho para se fortalecer. Há que se retomar e analisar criticamente essas generalizações produzidas ao longo de nossa história, tomando como referência questões como: A que serve o trabalho no modo de produção capitalista? Onde está colocado? Por que será que essa alternativa é colocada como "boa" apenas para crianças e adolescentes da classe trabalhadora? Refletir criticamente sobre essas questões tem fundamental importância (principalmente para os profissionais que atuam nessa área), pois a não compreensão dessas questões esvazia nossas lutas, como, por exemplo, de uma escola pública em período integral e de qualidade. 0 acesso a políticas sociais no campo da cultura, esporte e lazer ainda é visto como "privilégio" e não como um direito social e pré-condição de desenvolvimento integral de crianças e adolescentes.

Diretamente relacionado à questão anteriormente abordada, temos a terceira temática sinalizada, ou seja, a crescente "culpabilização das famílias", como as responsáveis individuais pelo sucesso e/ou dificuldades enfrentadas por crianças e adolescentes. Aqui também se pontua outra questão de grande complexidade, pois falar sobre família compreende um grande desafio e que não cabe nos limites deste texto. Porém, é importante registrar que esta vem passando por alterações no seu modo de constituição, organização e finalidade. Alterações que podem ser percebidas em suas novas formas de arranjos e nas formas de lidar com suas demandas individuais e/ou coletivas. E

Essas mudanças são fruto de um conjunto de fatores, entre os quais se destacam: a industrialização, a expansão do mercado consumidor, a incorporação da mulher à esfera do trabalho remunerado, o avanço nas técnicas de controle da natalidade e o movimento feminista. Mudanças que interferem na dinâmica familiar como um todo e, de forma particular, em cada família, conforme sua composição, história e pertencimento social. Trata-se, portanto, de uma transformação na instituição familiar, pois o que se observa é a produção de novos modos de ser entre homens, mulheres e seus filhos, entre adultos e crianças, partilhados por casais contemporâneos e que terminaram por constituir novas regras. (BRESSAN; GONÇALVES, 2016, p.241).

Diferentemente do acima referido, continua-se, por vezes, trabalhando com as famílias fundamentado na lógica inversa ao indicado. Se espera que ela tenha o papel de acompanhar e desempenhar os papéis mais tradicionalmente atribuídos à mesma. Aqui, novamente pode se identificar a retomada de vertentes conservadoras de interpretação do que vem a ser família e do papel social que lhe é atribuído. Não raramente identificamos embates que voltam a reafirmar a ideia clássica de família, refutando, discriminando e/ou segregando diferentes configurações familiares e suas crianças. Não se pode ter a ingenuidade de que esse debate se coloca apenas no campo conceitual, pois, seguramente, as políticas sociais não demorarão para incorporar essa perspectiva em seus programas e projetos, a exemplo das discussões que fundamentaram a constituição e aprovação do estatuto da família. 0 que possui um potencial devastador na atuação dos profissionais no campo social.

No que se refere às políticas sociais, Mioto (2010) afirma que vem crescendo essa tendência de terem um formato "familista" (que vem da ideia do familismo) presente nos mais diferentes sistemas de proteção social. Nessa perspectiva, as unidades familiares são consideradas as principais responsáveis pelo bem-estar de seus membros. Ocorrendo uma provisão menor de ações por parte do Estado, que se coloca na posição de somente agir quando for entendido que se está na situação de "falência da família", ou seja, quando é considerada "incapaz", passando a ser "objeto de ação" de políticas sociais - característica principal assumida a partir dos fundamentos neoliberais. 
Seriam inúmeras as questões a se debater sobre isso, mas duas tomam relevância no contexto da presente análise. Primeiramente, que as políticas públicas assumem uma caraterística de serem focalistas e pontuais. Estabelecem critérios de acesso cada vez mais restritivos e excludentes, onde famílias que não correspondem ao que então se entende como "modelo" têm seus acessos restringidos, mesmo considerando um contexto restritivo e de atuação focalizada. E, segundo, porém não menos importante, é a perda do caráter de serem objetivadoras de um direito social. Política pública que não se volta à universalidade (no sentido a que cada uma se propõe) nem como ação na dimensão protetiva das famílias e, por decorrência, de suas crianças e adolescentes.

E, finalmente como quarta questão aqui registrada, estão as propostas de alteração do ECA em tramitação na Câmara Federal, sob a forma de Projeto de Lei. Em um levantamento realizado de modo online (durante o mês de outubro de 2019) no site oficial da Câmara Federal, foram encontrados 73 Projetos de Lei (PLs) tramitando na referida casa que objetivavam alterar artigos do ECA. Esse conjunto de PLs contempla um total de 88 artigos a serem alterados. Do total geral dos projetos, 50 solicitam a alteração de um artigo; 13 solicitam a alteração de dois artigos; porém, 10 PLs solicitam alterações em três ou mais artigos do Estatuto ${ }^{5}$.

Tomando como referência a organização geral do ECA (parte geral e parte especial), das referidas solicitações, 41 delas (47\%) estão localizadas na parte geral; ou seja, naquela parte em que se concentram os títulos dos fundamentos mais gerais, ou do que denominamos da sua filosofia e do reconhecimento dos direitos fundamentais. E 47 propostas (53\%) estão localizadas na parte especial, ou seja, onde temos o estabelecimento de questões como diretrizes de funcionamento da política, proposição das ações especiais sob a forma de medidas (de proteção e socioeducativas), funcionamento de conselhos, como também as orientações/normatização do acesso à justiça.

As alterações da primeira parte estão concentradas principalmente no capítulo Do Direito à Vida e à Saúde (arts. 7º ao 14º), com 12 proposições, o que corresponde a $14 \%$ das indicações do bloco; seguindo-se Da Prevenção (arts. 70ํao 85) com 10 proposições, correspondendo a $11 \%$ das proposições; e, na sequência, Do Direito à Educação, à Cultura, ao Esporte e ao Lazer (arts. 53ㅜ ao 59) com oito, perfazendo 9\%; e Do Direito à Convivência Familiar e Comunitária (arts. 19aa 52º com sete indicações, com $8 \%$ dentre outras indicações com menor incidência de alterações.

No que se refere à parte especial, as propostas concentram-se mais no capítulo Dos Crimes e Das Infrações Administrativas (arts. 225ำ ao 267º), com 20 proposições, o que corresponde a 23\% das indicações desse bloco; e Da Prática de Ato Infracional (arts. 103 ao 130) com 15 proposições, o que corresponde a $17 \%$ das indicações desse bloco; ou seja, concentradas mais especificamente nos artigos que fazem referência à prática do ato infracional e à regulamentação das medidas socioeducativas. Conforme indicado anteriormente (quando analisadas as questões da redução da maioridade penal), é sabido que uma das principais estratégias a serem adotadas nessa temática não tem sido a via de alteração do artigo 228 da Constituição Federal, mas, sim, a alteração da forma de organização e funcionamento das medidas, onde essas assumem um caráter muito mais restritivo, punitivo, inclusive, com a significativa ampliação do tempo de internação e critérios para que se apliquem as medidas de internação.

Também é importante registrar que o espectro dos partidos políticos a que os autores das propostas estão vinculados concentra-se majoritariamente em perfis de direita, centro-direita

\footnotetext{
${ }^{5}$ Salienta-se que, neste momento, dado o estágio de análise dos dados da referida coleta e considerando a proposição do presente artigo, serão registrados aspectos gerais (preferencialmente os quantitativos) e com algumas incursões de conteúdo para que se tenha um cenário geral da temática. Análises mais detalhadas estão sendo realizadas e serão publicadas em artigo específico para a questão.
} 
e centro. A exemplo disso, temos o Partido Social Liberal (PSL), responsável por 10 das 73 sugestões de alterações; Partido da Social Democracia Brasileira (PSDB) e o Partido Podemos (PODE) responsáveis por nove; Partido Liberal (PL) por oito propostas; Republicanos (PRB) por sete; Partido Social Democrático (PSD) por seis; Democratas (DEM) por cinco; Partido dos Trabalhadores (PT) por três; Solidariedade (SOLIDARI), Partido Progressista (PP), Partido Popular Socialista (PPS), Partido Socialista Brasileiro (PSB) por duas; e Avante, Partido Social Cristão (PSC), Partido Republicanos (Republic), Partido Verde (PV), Partido Democrático Trabalhista (PDT), Patriota, Movimento Democrático Brasileiro (MDB), por uma, respectivamente.

Tomando como referência esse cenário, é importante afirmar que, aliada à crise econômica brasileira, vivenciada desde meados de 2013, observa-se a proliferação de movimentos de direita, pautada em um movimento ultraconservador, articulado a quatro níveis de forças: "economicamente liberal, moralmente reguladora, securitariamente punitiva e socialmente intolerante" (ALMEIDA, 2019, p. 1). Concomitantemente, no corpo social denota-se a oscilação de valores políticos, decorrente, sobretudo, do descrédito das forças políticas dos partidos de esquerda. Este cenário desemboca na eleição do atual Presidente da República Jair Bolsonaro, pautando-se na afronta aos direitos sociais e na Democracia Representativa, instituída por meio Constituição Federal de 88.

Como revela Souza (2015), “[...] frequentemente essa genealogia [do conservadorismo moderno não é explicitada ou assumida abertamente. Na maior parte das vezes, essas intervenções preferem apresentar-se como relativas à moderna democracia política (burguesa) [...]" (SOUZA, 2015, p. 6). Desmistificando que, "Em suma: quando o pensamento brasileiro 'importa' uma ideologia universal, isso é prova de que determinada classe ou camada social de nosso país encontrou (ou julgou encontrar) nessa ideologia a expressão de seus próprios interesses brasileiros de classe ...". (COUTINHO, 2011, apud, SOUZA, 2015)

Em síntese, os elementos acima indicados oferecem todos os indicativos confirmadores das questões para as quais vimos chamando atenção ao longo deste item, principalmente no que diz respeito, então, à possibilidade concreta da (re)afirmação do "antigo". Estes representam a expressão concreta do "contramovimento" indicada inicialmente. Em outras palavras, está posta concreta e objetivamente a possibilidade de termos significativos retrocessos com questões que alteram fundamentalmente a luta de afirmação e reconhecimento da condição especial e peculiar da infância e adolescência brasileiras travada por mais de três décadas.

\section{Considerações finais}

A partir das concepções e dados apresentados no decorrer do texto, observa-se ser necessário compreender as conquistas efetivadas pelo Estatuto, na perspectiva de garantir direitos de crianças e adolescentes. Contudo, devem-se levar em conta as desigualdades sociais e econômicas ocasionadas pela lógica capitalista, aprofundadas no contexto de pandemia do novo Coronavírus. Conjuntura que emana de uma crise no sistema do capital, crise social, econômica e agravada no presente momento pela crise sanitária.

Visto isso, apreende-se que o momento atual (de pandemia) agrava as condições de vida e sobrevivência das famílias, aumentando quantitativamente os sujeitos em situação de miséria e extrema pobreza, provocada pela ampliação do desemprego, trabalhos informais e precarizados. E, especificamente, na área da criança e do adolescente, acarreta a ampliação dos índices de trabalho infantil; violência doméstica, física, psicológica e sexual; homicídios de crianças e 
adolescentes oriundos da classe subalterna e periférica; desigualdade educacional, considerando que muitos não possuem acesso à Internet e ambientes favoráveis ao estudo em casa; doenças e transtornos psicológicos, como ansiedade e depressão; e baixa fonte de alimentação, haja vista que alguns realizavam suas refeições apenas ou majoritariamente no ambiente escolar; entre outras problemáticas que estão aliadas à subnotificação aos canais de denúncia e atendimento a esse público.

Nesse sentido, a conjuntura revela um cenário político-social adverso à lógica de garantia de direito, intensificando as desigualdades históricas e sociais da sociedade brasileira, que, por vezes, reforça a retomada do caráter coercitivo e punitivo pautado no Código de Menores. Nesta direção, tem-se, por exemplo, as 73 propostas de alteração do Estatuto (já sintetizados no corpo deste documento), dentre as quais, algumas expõem a dicotomia histórica crianças versus menores - caracterização para crianças oriundas das classes subalternas.

Com base nesses aspectos e posições, enfatiza-se a necessidade de qualificação profissional dos atores do SGD, por intermédio de formações e capacitações continuadas que ofertem estudos aprofundados no ECA e nas temáticas que se relacionam a este; o aperfeiçoamento e reparação de infraestruturas institucionais; e, sobretudo, a articulação da rede de serviços e sujeitos que compõem o SGD.

Conclui-se que o trabalho em rede se converte em oportunidade de reunir os diversos sujeitos (sem esquecer que as crianças e adolescentes também se configuram como sujeitos de direitos e protagonistas) e instituições que possuem interesses comuns, construindo, desta forma, um trabalho integrado. Vê-se que, por intermédio da atuação coletiva, pode ocorrer a prevenção da violação dos direitos da infância e adolescência. Por fim, reitera-se a importância da luta e mobilização da sociedade, para reafirmação constante da garantia dos direitos de crianças e adolescentes instituídos pelo ECA.

\section{Referências}

ALMEIDA, Ronaldo. Bolsonaro Presidente: Conservadorismo, Evangelismo e a Crise Brasileira.

Novos estudos CEBRAP, São Paulo, v. 38, n. 1, 2019. Disponível em: https://www.scielo.br/scielo. php?script=sci_arttext\&pid=S0101-33002019000100010\&lang=pt

ANFIP. Desigualdade Distributiva, Carga Tributária e Incidência Tributária no Brasil. In. Sistema Tributário e Seguridade Social: Contribuições para o Brasil. $2^{\mathrm{a}}$ edição Revista, ampliada e atualizada. Brasília, jun. 2014. p. 15- 24. Disponível em: https://www.anfip.org.br/wp-content/uploads/2019/02/ sistema_tributario_final.pdf

BAPTISTA, Myrian Veras. Algumas reflexões sobre o sistema de garantia de direitos. Serviço Social e Sociedade. São Paulo: Cortez, n.109, jan/mar.2012. p. 179- 199.

BRASIL. ANUÁRIO BRASILEIRO DE EDUCAÇÃO BÁSICA 2018. Todos pela Educação. Relatório. Editora Moderna. Brasil. 2018. Disponível em: https://todospelaeducacao.org.br/_uploads/20180824-Anuario_ Educacao_2018_atualizado_WEB.pdf?utm_source=conteudoSite

BRASIL. Débora Brito. Senado Federal. Gravidez precoce ainda é alta, mostram dados. 2017. Disponível em: https://www12.senado.leg.br/noticias/especiais/especial-cidadania/gravidez-precoceainda-e-alta-mostram-dados. Acesso em: 27 jul. 2020.

BRASIL. Lei 8.069, de 13 de julho de 1990. Estatuto da Criança e do Adolescente. Brasília. Disponível em: http://www.planalto.gov.br/ccivil_03/leis/l8069.htm 
BRASIL. Ministério da Educação. Nota Técnica Conjunta no: Pareamento de dados do Programa PBC na escola referente ao ano de 2017. Brasil, 2018. Disponível em: http://portal.mec.gov.br/index. php?option=com_docman\&view=download\&alias=98771-nota-tecnica-conjunta-n-2-2018-pareamento2017\&category_slug=outubro-2018-pdf-1\&Itemid=30192

BRASIL. Ministério da Saúde. "VIVA: Vigilância de Violências e Acidentes". Brasília: DF. 2017. Disponível em:http://bvsms.saude.gov.br/bvs/publicacoes/viva_vigilancia_violencia_ acidentes_2013_2014.pdf

BRASIL. Ministério da Saúde. Secretaria de Atenção Primária À Saúde. Prevenção e Controle de Agravos Nutricionais. 2020 Disponível em: https://aps.saude.gov.br/ape/pcan/ desnutricao\#: :text=De\%20acordo\%20com\%20dados\%20do,um\%20total\%20de\%2022.194\%20 crian\%C3\%A7as. Acesso em: 27 jul. 2020.

BRASIL. Secretaria dos Direitos Humanos. Cadastro Nacional dos Conselhos Tutelares. Brasília, 2013. Disponível em: http://www.mpap.mp.br/images/infancia/Cadastro_CT.pdf

BRASIL. Secretaria dos Direitos Humanos. PLANO NACIONAL DE ATENDIMENTO SOCIOEDUCATIVO: Diretrizes e eixos operativos para o SINASE. Brasília, 2013. Disponível em: http://www.mpgo.mp.br/ portal/arquivos/2017/03/03/17_49_45_295_Plano_NACIONAL_Socioeducativo.pdf

BRASIL. Secretaria de Direitos Humanos. Direitos Humanos de Crianças e Adolescentes - 20 anos do Estatuto. Brasília, DF: Secretaria de Direitos Humanos, 2010.

COSTA, Antônio Carlos Gomes da. Princípios do Estatuto da Criança e do Adolescente. Canal Promenino. 2011. Vídeo (11min). Disponível em: https://www.youtube.com/watch?v=It-bZaFuXP0 DIGIÁCOMO, Murillo José. o Sistema de Garantias de Direitos da Criança e do Adolescente e o desafio do trabalho em "rede". Publicado em 1o outubro 2011. Disponível em: http://www.crianca. caop.mp.pr.gov.br/modules/conteudo/conteudo.php? conteudo=1129.

DIÁRIO CATARINENSE, Santa Catarina, 12 de junho 2018.Disponível em: https://www.nsctotal.com. $\mathrm{br} /$ noticias/trabalho-infantil-e-triste-realidade-em-sc-diz-procuradora. Acesso em: 28 de julho 2020.

GAZETA ONLINE. Bolsonaro diz que Estatuto da Criança e do Adolescente deve ser jogado na latrina. 2018. Disponível em: https://www.gazetaonline.com.br/noticias/politica/ eleicoes_2018/2018/08/bolsonaro-diz-que-estatuto-da-crianca-e-do-adolescente-deve-ser-jogado-nalatrina-1014145442.html. Acesso em: 27 jul. 2020.

IBGE. Brasil em síntese. Taxa de Mortalidade Infantil por mil nascidos vivos - Brasil - 2000 a 2015. 2020. Disponível em: https://brasilemsintese.ibge.gov.br/populacao/taxas-de-mortalidade-infantil. html. Acesso em: 27 jul. 2020.

MIOTO, Regina Célia. Família, Trabalho com Famílias e Serviço Social. Serviço Social em Revista, Londrina, v. 2, n. 12, p. 163-176, jan/jun. 2010. Disponível em: http://www.uel.br/revistas/uel/index. $\mathrm{php/ssrevista/article/view/7584/6835}$

PARANÁ. Ministério Público do Paraná. Ministério Público do Paraná. Disque 100 - Disque Direitos Humanos - Disque Denúncia Nacional. Disponível em: http://crianca.mppr.mp.br/pagina-3.html. Acesso em: 28 jul. 2020.

$5^{\circ}$ RELATÓRIO NACIONAL SOBRE OS DIREITOS HUMANOS NO BRASIL (2001-2010). Núcleo de Estudos da Violência da Universidade de São Paulo (NEV-USP). São Paulo. 2012. Disponível: http:// www.usp.br/imprensa/wp- content/uploads/5\%C2\%BA-Relat\%C3\%B3rio-Nacional-sobre-os-DireitosHumanos-no-Brasil-2001-2010.pdf 
REDE BRASIL ATUAL. Em meio aos ataques do governo Bolsonaro, ECA completa 29 anos. 2019. Disponível em: https://www.redebrasilatual.com.br/cidadania/2019/07/em-meio-aos-ataques-dogoverno-bolsonaro-eca-completa-29-anos/. Acesso em: 27 jul. 2020.

RIBEIRO, Vera Masagão. Alfabetismo funcional: referências conceituais e metodológicas para a pesquisa. Educ. Soc., Campinas, v. 18, n. 60, p. 144-158, Dez. 1997. Disponível em: https://www.scielo. br/scielo.php?script=sci_arttext\&pid=S0101-73301997000300009\&lng=en\&nrm=iso

SILVA, M.Liduína. Estatuto da Criança e do adolescente e o Código de Menores: descontinuidades e continuidades. Serviço Social e Sociedade. São Paulo: Cortez, ano XXVI, n.83, set. 2005. Pag. 30-48.

SOUZA, Jamerson Murillo Anunciação de. O conservadorismo moderno: esboço para uma aproximação. Serviço Social \& Sociedade, n. 122, p.199-223, jun. 2015. FapUNIFESP (SciELO). http:// dx.doi.org/10.1590/0101-6628.020. Disponível em: http://www.scielo.br/scielo.php?script=sci_ arttext\&pid=S0101-66282015000200199\&lang=pt

TEJADAS, Silvia. Juventude e ato infracional: o sistema socioeducativo e a produção da reincidência. Revista Digital do Ministério Público do Rio Grande do Sul. 2005. Disponível: http:// www.mprs.mp.br/areas/infancia/arquivos/revista_digital/numero_01/revista_digital_ed_01_3.pdf

WACQUANT, Loic. As prisões da miséria. São Paulo. Zahar, 1994.

WAISELFIZ, Julio Jacobo. Violência Letal Contra as Crianças e Adolescentes Do Brasil. Relatório de pesquisa - Faculdade Latino-Americana de Ciências Sociais (Flacso). Brasil, 2015. p. 1-152. Disponível em: http://flacso.org.br/files/2016/06/Viol\%C3\%AAncia_Letal_web.pdf 